\title{
Laboreal
}

Volume $16 \mathrm{~N}^{\circ} 2$ | 2020

Programa de Pesquisa do Curso da Ação

\section{Recensão crítica do livro de Francisco Antonio de Castro Lacaz, Patrícia Martins Goulart e Virginia Junqueira (2017) - Trabalhar no SUS: gestão, repercussões psicossociais e política de proteção à saúde}

Análisis crítico de la obra de Francisco Antonio de Castro Lacaz, Patrícia Martins Goulart y Virginia Junqueira (2017) - Trabajar en el SUS: gestión, repercusiones psicosociales y política de protección de la salud Analyse critique de l'ouvrage de Francisco Antonio de Castro Lacaz, Patrícia Martins Goulart et Virginia Junqueira (2017) - Travailler au SUS : gestion, répercussions psychosociales et politique de protection de la santé Review of the book of Francisco Antonio de Castro Lacaz, Patrícia Martins Goulart and Virginia Junqueira (2017) -Working at SUS: management, psychosocial repercussions and health protection policy

\section{Arthur Chioro}

\section{(2) OpenEdition}

\section{Journals}

\section{Edição electrónica}

URL: http://journals.openedition.org/laboreal/16662

DOI: $10.4000 /$ laboreal. 16662

ISSN: 1646-5237

Editora

Universidade do Porto

Refêrencia eletrónica

Arthur Chioro, « Recensão crítica do livro de Francisco Antonio de Castro Lacaz, Patrícia Martins Goulart e Virginia Junqueira (2017) - Trabalhar no SUS: gestão, repercussões psicossociais e política de proteção à saúde », Laboreal [Online], Volume 16 №2 | 2020, posto online no dia 01 dezembro 2020 consultado o 14 dezembro 2020. URL : http://journals.openedition.org/laboreal/16662 ; DOI : https:// doi.org/10.4000/laboreal.16662

Este documento foi criado de forma automática no dia 14 dezembro 2020

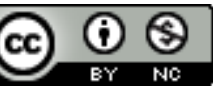

Laboreal está licenciado com uma Licença Creative Commons - Atribuição-NãoComercial 4.0 Internacional. 


\section{Recensão crítica do livro de Francisco Antonio de Castro Lacaz, Patrícia Martins Goulart e Virginia Junqueira (2017) - Trabalhar no SUS: gestão, repercussões psicossociais e política de proteção à saúde}

Análisis crítico de la obra de Francisco Antonio de Castro Lacaz, Patrícia Martins Goulart y Virginia Junqueira (2017) - Trabajar en el SUS: gestión, repercusiones psicosociales y política de protección de la salud Analyse critique de l'ouvrage de Francisco Antonio de Castro Lacaz, Patrícia Martins Goulart et Virginia Junqueira (2017) - Travailler au SUS : gestion, répercussions psychosociales et politique de protection de la santé Review of the book of Francisco Antonio de Castro Lacaz, Patrícia Martins Goulart and Virginia Junqueira (2017) -Working at SUS: management, psychosocial repercussions and health protection policy

Arthur Chioro

\section{REFERÊNCIA}

Referência do livro : Lacaz, F. A. de C., Goulart, P. M., \& Junqueira, V. (2017). Trabalhar no SUS: gestão, repercussões psicossociais e política de proteção à saúde. São Paulo: Hucitec 


\section{NOTA DO EDITOR}

Manuscrito recebido em : 17/06/2020

Aceite após peritagem : 06/08/2020

\section{Como será a vida no mundo pós-pandemia de Sars- Cov-2?}

1 Como será a vida no mundo pós-pandemia de Sars-Cov-2 é ainda uma incógnita, repleta de dúvidas e, por enquanto, poucas respostas. Entre as certezas que emergem de uma análise preliminar da crise sanitária a que fomos submetidos em escala global, duas estão diretamente relacionadas ao livro aqui resenhado. A primeira, é o inédito e elevado grau de visibilidade que a pandemia de Covid-19 proporcionou aos sistemas nacionais de saúde, seus serviços de saúde e, em particular, aos trabalhadores da saúde. As cenas transmitidas em tempo real expressam insuficiências, desorganização e a necessidade de improvisar frente à saturação de serviços de cuidados críticos, mesmo em países do hemisfério norte considerados ricos. Mostram, por outro lado, a árdua labuta de médicos, enfermeiros e outros profissionais, dedicando-se a extenuantes jornadas laborais, fortemente paramentados, anônimos e muitas vezes atônitos, como peças de uma grande engrenagem, expostos a riscos, para cada um e suas famílias. 0 reconhecimento público da dedicação dos trabalhadores da saúde, identificados como heróis e heroínas pós-modernas (já que a maioria é constituída por mulheres), aos cuidados dos enfermos, protegendo e lutando por suas vidas, abre a possibilidade de lançar luz sobre o valor de uso da saúde e a necessidade de reconhecer o caráter essencial da saúde na produção da vida, bem como a de valorizar o trabalho e de garantir condições dignas de trabalho em saúde. Tornou-se possível, como nunca antes, fazer o debate e a disputa pública sobre o direto à saúde como um direito social, universal e integral, e reivindicar os investimentos necessários para o fortalecimento e sustentabilidade de sistemas nacionais de saúde, temas interditados até então em função da hegemonia do discurso econômico que impôs, em todo o mundo, a adoção de políticas de saúde centradas na austeridade fiscal e na privatização dos serviços de saúde, que se demonstraram incapazes de responder aos imperativos de proteger a vida e a saúde das populações (Menezes et al., 2019). Trata-se de cálculo apartado ou negligenciado na formulação de políticas públicas, num mundo cada vez mais pautado pela lógica neoliberal, agora colocada em xeque pela pandemia de Sars-Cov-2 e pelos efeitos da crise econômica por ela potencializados. A segunda certeza é a de que o trabalho, como hoje entendido, será profundamente reconfigurado no "novo normal", tanto para atender exigências advindas das transformações nas condições e na organização do processo de trabalho, como aquelas resultantes da invasão do teletrabalho no mundo da vida, em escala até então não experimentada. Ferramentas digitais utilizadas durante o período de isolamento social se associam agora aos diferentes dispositivos e estratégias de exploração da força de trabalho, tomando conta de todos os domínios, invadindo a privacidade, o lar e cada segundo do tempo disponível dos trabalhadores. Tais mudanças indicam profundas transformações no mundo do trabalho e o uso intensivo da informática se coloca como mais um dispositivo permitindo dar sustentação e aprofundar aquilo que Bourdieu (1998) denominou "restauração da ordem conservadora", em curso há várias décadas nos países 
capitalistas centrais e agora, de forma cada vez mais voraz, nos países de baixa e média renda. É nesse contexto que se inscrevem os ataques ao trabalho em saúde, antecipados já no prefácio do livro, de autoria de Áquilas Mendes, operados a partir da lógica da expropriação do trabalho, privatização e mercantilização da saúde, precarização das condições e vínculos de trabalho, extensão das jornadas, entre outras características, que repercutem e estão diretamente relacionadas com o adoecimento físico e mental dos trabalhadores.

\section{O legado de Francisco Lacaz}

2 O livro "Trabalhar no SUS: gestão, repercussões psicossociais e política de proteção à saúde", organizado pelos pesquisadores brasileiros Francisco Antonio de Castro Lacaz, Patrícia Martins Goulart e Virginia Junqueira e publicado pela Hucitec, foi produzido por autores reconhecidos do campo da Saúde Coletiva e da Saúde do Trabalhador. Busca apresentar os resultados da pesquisa - e os produtos acadêmicos dela resultante, como três dissertações de mestrado e duas teses de doutorado -, de caráter qualiquantitativo, realizada entre 2012 e 2014 em dois municípios brasileiros de grande porte populacional pelo grupo de pesquisa da Universidade Federal de São Paulo liderado por Francisco Lacaz.

3 Na verdade, o livro coroa o legado de mais de quatro décadas dedicadas ao ensino, à pesquisa e intervenções militantes junto ao movimento operário realizadas no campo da Saúde do Trabalhador pelo Professor Francisco Lacaz, constituindo uma referência obrigatória no campo da Saúde do Trabalhador no Brasil.

4 Trata-se assim de uma produção implicada, produzida por sujeitos epistêmicos militantes (Merhy, 2004) que buscam analisar criticamente a gestão do trabalho em saúde e ao mesmo tempo fornecer subsídios aos gestores municipais na perspectiva do estabelecimento de políticas de prevenção de agravos e de promoção à saúde dos trabalhadores da saúde.

O referencial teórico-conceitual utilizado se assenta no campo de práticas e saberes denominado Saúde do Trabalhador, que toma como objeto de estudo as relações entre processos de trabalho e saúde, e como categoria central o conceito de processo de trabalho sob a perspectiva marxista, buscando uma abordagem para além da medicina do trabalho e da saúde ocupacional. Lança mão, ainda, das contribuições: da Saúde Coletiva, considerando a determinação social do processo saúde/doença e, nesta, a categoria trabalho como essencial; do Modelo Operário Italiano; das contribuições da Medicina Social Latino-americana e da própria Saúde Pública.

\section{Um livro em oito capítulos}

O livro está disposto em oito capítulos. No capítulo 1, a gestão do trabalho e o Sistema Único de Saúde (SUS) são discutidos, já sob o "reinado do mercado", à luz da produção das políticas neoliberais, da perspectiva de reformas e atualização do papel do Estado (de empresário a gerente), da tensão entre o público e o privado e do gerencialismo, que permeiam toda a obra, que dialoga consistente e criticamente seus fundamentos e principais consequências, com ênfase para a precarização das condições e processos de trabalho, privatização e privilegiamento de resultados em detrimento de processos. No 
capítulo 2 são apresentados os aspectos metodológicos e instrumentos da pesquisa. No capítulo 3, diferentes aspectos teóricos e empíricos da gestão do trabalho em saúde são abordados, apontando para a discussão da precarização do trabalho na saúde para além da dimensão burocrático-administrativa, e da dinâmica interior do processo de trabalho, envolvendo as formas de contratação e vínculo, a organização da jornada de trabalho, as relações de mando e do estranhamento no trabalho contemporâneo. 0 capítulo 4 destina-se à análise das repercussões da gestão do trabalho sobre a saúde e o sofrimento físico e mental dos trabalhadores da saúde dos dois municípios, apontando dados de afastamento do trabalho por doença, suas possíveis causas e sugestões de intervenção. 0 Capítulo 5 , produzido a partir de uma consistente revisão sistemática da literatura, aborda as repercussões psicossociais e as estratégias de resistência e de enfrentamento adotadas pelos trabalhadores em relação aos constrangimentos da gestão e seus reflexos sobre os processos e condições de trabalho, a partir de contribuições da Psicologia Social, da Psicopatologia, da Psicodinâmica do Trabalho e da Qualidade de Vida n(d)o Trabalho. Já no Capítulo 6, são consideradas a estrutura e atuação de órgão existente num dos municípios estudados na área da assistência, prevenção e promoção da saúde dos trabalhadores municipais. Em seguida, no Capítulo7, a partir da aplicação do questionário Estudo de Qualidade de Vida no Trabalho (EQVT) adaptado, são analisadas a Gestão do Trabalho em Saúde e as repercussões psicossociais na visão de médicos e enfermeiros. Finalmente, no oitavo e último capítulo, as recomendações da pesquisa embasam a proposição de uma Política de Saúde do Trabalhador da Saúde no âmbito municipal, concebida a partir da atuação intra e intersetorial; da ruptura da dicotomia entre assistência e vigilância em saúde, na perspectiva da prevenção e promoção; do envolvimento de distintos órgãos, de diferentes esferas de governo, que atuam na saúde dos trabalhadores nos municípios; e, do protagonismo e ampla participação social dos sujeitos diretamente interessados.

\section{Duas questões sensíveis}

7 Dois temas realçados nesta obra nos parecem merecer toda a atenção dos leitores.

8 O primeiro é relativo à implementação de Planos de Cargos, Carreiras e Salários (PCCS), em contexto político e econômico crítico. Ainda que seja de fato um interessante dispositivo analítico, é necessário reconhecer que o PCCS é uma ferramenta de gestão que foi pouco considerada na administração pública brasileira, seja por gestores seja pelos próprios trabalhadores e suas representações sindicais, como o empírico produzido na pesquisa evidencia. Mas é preciso considerar que a Administração Pública nunca tratou como prioridade a implantação dos PCCS, em particular no âmbito do SUS, porque seus postulados antagonizam com os princípios fundantes da Nova Gestão Pública.

9 Outro questão para a qual queríamos abrir aqui o debate, diz respeito ao projeto de construção de uma política de saúde do trabalhador da saúde no âmbito municipal no quadro de uma intervenção da pesquisa participante que acaba por nem sempre poder contar com o efetivo protagonismo dos trabalhadores e/ou de suas representações sindicais. Tal constatação, analisada pelos autores, é provavelmente fruto e reflexo dos tempos que vivemos, marcados pelo individualismo e pela fragilização da produção de redes coletivas e solidárias capazes de incidir na correlação de forças dos processos sociais em disputa. Mas é verdade que as situações em causa foram moldadas por 
diretrizes e dispositivos da Política Nacional de Saúde do Trabalhador que, embora resultantes do acúmulo produzido pelos diferentes atores envolvidos, acabaram por reproduzir o desenho tradicional de formulação de políticas públicas, do tipo top-down.

\section{Um legado que terá os seus continuadores}

10 O livro termina sem um capítulo destinado às conclusões ou considerações finais, deixando o leitor instigado e convidado a refletir sobre os desdobramentos, a partir de 2016, tomados pela politica de saúde do trabalhador da saúde no âmbito municipal, desencadeada a partir dos resultados do estudo e impactadas pela pesquisa participante. Para compreender tal "deslize editorial" impõe-se o reconhecimento de um pressuposto que margeia explicitamente o referencial teórico adotado pelos autores, para quem a gestão do trabalho em saúde é, para além de uma questão de tecnicidade, um constructo político. Aqui, não podemos deixar de referir que o Brasil enfrentou um agravamento da crise econômica, que atingira o país a partir de 2014, e sua democracia foi abalada por um golpe jurídico-político-midiático que depôs a presidente legitimamente eleita, em 2016, em um movimento alinhado com a onda conservadora que varreu o mundo, atingindo fortemente, em particular, governos democráticos e populares da América Latina. Ao lado disso ocorreu a aprovação de uma emenda à Constituição Federal, em dezembro de 2016, a qual resultou na adoção de um Novo Regime Fiscal (Orçamental) que instituiu um regime de austeridade, com o congelamento dos gastos públicos por 20 anos, além da aprovação de uma reforma trabalhista e da previdência social que desregulamentaram direitos elementares, resultantes de conquistas históricas dos trabalhadores, agravando as condições de precarização, insegurança e exploração da força de trabalho (Reis et al., 2016). Os efeitos dessas medidas para a política de saúde e o SUS são extremamente graves (Reis, 2018). Na esteira de uma reforma dessa magnitude, o diagnóstico que se delineia é a destruição das políticas públicas, com forte impacto sobre os serviços e os trabalhadores da saúde, inclusive os trabalhadores do serviço público, apontados como bodes expiatórios pelos males da sociedade. Além disso, a conjuntura conservadora e a demonização das esquerdas abriram espaço para o cenário traçado e discutido em profundidade no livro organizado por Lacaz, Goulart \& Junqueira.

11 O Brasil, para além das contradições e resistências experimentadas desde a redemocratização e da aprovação da Constituição Federal de 1988, enquadrou-se definitivamente na ordem neoliberal. Todavia, coerente com o propósito condutor do livro, que se pauta fortemente no materialismo histórico e na visão de que a política é determinante dos processos sociais, e que a ação humana (e coletiva) é decisiva para delinear o desfecho da história, parece-nos restar um desafio que termina em aberto, como uma espécie de convite para que os pesquisadores mais jovens do grupo e outros investigadores brasileiros e de outros países, que se dedicam a estudar os processos de gestão do trabalho em saúde, possam escrever, a partir do esforço investigativo e da produção de conhecimentos engajados com uma certa visão de mundo, ainda contrahegemônica, os próximos capítulos. 


\section{BIBLIOGRAFIA}

Menezes A. P. R., Moretti B., \& Reis, A. A. C. (2019). o futuro do SUS: impactos das reformas neoliberais na saúde pública - austeridade versus universalidade. Saúde Debate, 43(5), 58-70. http://dx.doi.org/10.1590/0103-11042019S505

Bourdieu, P. (1998). Contrafogos: táticas para enfrentar a invasão neoliberal. Rio de Janeiro: Jorge Zahar Ed.

Merhy, E. E. (2004). O Conhecer Militante do Sujeito Implicado: O Desafio em Reconhecê-lo como saber válido. In: Franco, T.B. e col. Acolher Chapecó: uma experiência de mudança do modelo assistencial, com base no processo de trabalho (pp. 21-45). São Paulo: Editora Hucitec.

Reis, A. A. C., Soter, A. P. M., Furtado, L. A. C., \& Pereira, S. S. S. (2016). Tudo a temer: financiamento, relação público e privado e o futuro do SUS. Saúde Debate, 40, 122-135. http:// dx.doi.org/10.1590/0103- 11042016s11

Reis, A. A. C. (2018). O que será do Brasil e do SUS? Reciis - Rev Eletron Comun Inf Inov Saúde, 12(2), 119-24. https://doi.org/10.29397/reciis.v12i2.1551

\section{AUTOR}

\section{ARTHUR CHIORO}

Universidade Federal de São Paulo. Escola Paulista de Medicina. Departamento de Medicina Preventiva. Rua Botucatu, 740, Vila Clementino, São Paulo-SP (Brasil). CEP 04023-062; arthur.chioro@unifesp.br 